\title{
O FAZER ARTETERAPÊUTICO COMO ABORDAGEM DE INTERVENÇÃO PSICOPEDAGÓGICA DESENVOLVIDO COM UMA CRIANÇA AFETADA POR INIBIÇÃO COGNITIVA: UM ESTUDO DE CASO
}

\author{
Janaína Bueno Bady ${ }^{1}$ \\ Canoas, Rio Grande do Sul, Brasil.
}

\section{RESUMO}

Este artigo apresenta o caso clínico de um menino de oito anos com um quadro de inibição cognitiva que com uma adequada intervenção psicopedagógica embasada no tratamento com Arteterapia superou o obstáculo que aprisionava sua inteligência. Descrevemos as causas e o funcionamento desse problema que bloqueava seu desenvolvimento integral, afetando, principalmente, seu desempenho escolar. Pretendemos, deste modo, salientar o papel do psicopedagogo neste processo e revelar o alcance do trabalho terapêutico com a arte.

Palavras-chave: Inibição Cognitiva, Intervenção Psicopedagógica, Desenvolvimento Global, Arteterapia.

\footnotetext{
${ }^{1}$ Especialista em Psicopedagogia Clínica e Institucional e Mestra em Educação. Rua Tomé de Souza, 120 - N. Sra. das Graças - Canoas - RS. E-mail: jana.aletheia@gmail.com
} 


\section{THE ART THERAPY AS A PSYCHOPEDAGOGICAL INTERVENTION APPROACH DEVELOPED WITH A CHILD SUFFERING FROM COGNITIVE INHIBITION: A CASE STUDY}

\section{ABSTRACT}

This article presents the clinical case of eight years old boy with a clinical feature of cognitive inhibition with an appropriate pedagogical intervention grounded in art therapy treatment he overcame the obstacle that imprisoned his intelligence. We describe the causes and operation of this problem that blocked his integral development, affecting mainly their school performance. We intend, therefore, to emphasize the role of psychopedagogists this process and reveal the extent of therapeutic work with art.

Keywords: Cognitive Inhibition, Psychopedagogical Intervention, Global Development, Art Therapy.

\section{Introdução}

Neste trabalho incorporamos, dentre outros, o conceito de aprendizagem de Alícia Fernández (1991), entendendo-a como um processo e uma função, que ultrapassa o âmbito escolar e que não diz respeito exclusivamente à criança. Neste processo estão implicados quatro níveis do ser humano (organismo, corpo, inteligência, desejo). Deste modo, a aprendizagem passa pelo corpo, temos o corpo presente em todos os tipos de aprendizagem, não apenas como ato, mas também como prazer, já que o prazer está no corpo.

A aprendizagem necessita do desejo do aprendente e do ensinante e, sobretudo, do vínculo que se estabelece entre ambos. Sara Paín (1991) define a aprendizagem como um processo no qual um outro que sabe transmite o conhecimento a um sujeito que vai chegar a ser sujeito, exatamente por meio da aprendizagem.

Weiss (2008) destaca a ideia de aprendizagem como um processo de construção que ocorre através da interação contínua do sujeito com o seu meio (família, escola, sociedade). Vygotsky (1988) também aponta que toda a aprendizagem da criança tem uma pré-história, frisando que essa começa muito antes da aprendizagem escolar.

Sabemos que as dificuldades de aprendizagem possuem múltiplas causas, aspectos orgânicos, cognitivos, emocionais, sociais e pedagógicos interferem no processo ensino-aprendizagem (WEISS, 2008). Sendo assim, o sucesso de um diagnóstico reside, sobretudo, na capacidade do terapeuta em explorar os múltiplos aspectos revelados em cada circunstância. Pichon-Rivière (2007) diz que o foco da análise não deve restringir-se ao paciente, mas ampliar-se às suas relações, aos grupos e às instituições aos quais pertence.

Ainda hoje profissionais da saúde e da educação acreditam que grande parte dos transtornos de aprendizagem tem etiologia orgânica, ou são originários de quadros psiquiátricos, ou dizem respeito às etapas da evolução psicossocial, ou vinculam-se à estrutura da inteligência, ou podem ser compreendidos em função de causas emocionais ou familiares, como se somente cada um desses fatores isoladamente fosse capaz de determinar e de explicar o problema de aprendiza- 
gem. Esses não podem ser negados enquanto influências reais, no entanto, detendo-se exclusivamente em uma dessas causas estaremos parcializando nosso olhar sobre o problema, já que esses fatores não são suficientes ou não são vistos aqui por nós como causas determinantes dos problemas do aprender.

Trabalharemos, então, com a perspectiva de Alicia Fernández (1991), visando encontrar a relação subjetiva do indivíduo com o conhecimento e o significado do aprender. A autora acredita que o problema de aprendizagem que afeta o sujeito sintomatiza e surge na trama vincular de seu grupo familiar, podendo ser mantido pela instituição escolar. Bolwby (2006) acredita que os problemas vinculados à apropriação do conhecimento surgem porque os pais possuem dificuldades emocionais e atuam com emoções ambivalentes de que estão parcialmente conscientes e que não podem controlar, gerando, desse modo, uma dificuldade nos filhos desde a infância. Sob a luz do viés psicanalítico sabemos que o saber é almejado, mas inconscientemente sentido como um perigo desde os primórdios do homem. A vontade de saber paradoxalmente tramita no indivíduo com a vontade de não saber, esse jogo e suas articulações originam nós e travas psicoemocionais, bloqueando a dinamicidade da busca do conhecimento, conforme ainda Fernández (1991).

Discutiremos neste artigo esse tipo de mobilização que gera o fracasso escolar, devido a uma inibição cognitiva. Fernández (1991) compreende essa como um bloqueio que afeta o sujeito e a dinâmica de articulação entre os níveis de inteligência, desejo, organismo e corpo, resultando num aprisionamento da inteligência e da corporeidade do indivíduo e afetando sua estrutura simbólica inconsciente.

Sendo assim, Alicia diz que caberá ao psicopedagogo investigar qual é a posição da criança diante dos segredos familiares, frente ao não-dito, frente ao imaginário e ao real, já que é a impossibilidade de simbolizar que provoca a fratura na aprendizagem ou o sintoma do não-aprender ou das dificuldades em aprender. No diagnóstico psicopedagógico é importante encontrarmos para auxílio da família a funcionalidade inconsciente do não-aprender, encontrar para que serve ao sistema familiar a não-aprendizagem de um de seus membros. De que modo, durante a história de vida da criança, a família contribuiu para determinados bloqueios na criança. Assim, é necessário que não observemos a criança que não aprende somente como uma consequência, mas como um sintoma de uma particular situação vincular e social.

Alícia Fernández (1991) acredita que o profissional de Psicopedagogia deve considerar o problema de aprendizagem como resultado da articulação construtiva do organismo, corpo, inteligência e a estrutura do desejo da pessoa incluída num grupo familiar no qual o seu sintoma tem sentido e funcionalidade e numa instituição educacional, que também o condiciona e o significa. O psicopedagogo, desse modo, deve buscar libertar a inteligência e mobilizar a circulação patológica do conhecimento em seu grupo familiar.

Para tal, Weiss (2008) alerta-nos a discernir com critério o que são dificuldades ao processo de construção do conhecimento, ligadas aos domínios afetivos e cognitivos, o que são questões ligadas a quadros que poderão indicar dificuldades orgânicas, necessitando assim, diagnóstico e intervenção de outros profissionais, e aquilo que se relaciona à má-condução do processo didático-pedagógico da escola. Tais aspectos exigirão do terapeuta, sobretudo, a construção de um olhar e de uma escuta a partir de uma análise de seu próprio aprender, bem como a valorização e o dar sentido a quem fala, possibilitando o auto entendimento do outro a partir do ser ouvido.

Weiss acredita que durante o diagnóstico e a intervenção psicopedagógica devemos propiciar situações que tenham significado para o paciente, fazendo uso de recursos como dramatização, 
O fazer arteterapêutico como abordagem de intervenção psicopedagógica desenvolvido com uma criança afetada por inibição cognitiva: um estudo de caso

histórias, músicas, desenhos, pinturas e observar como este se aproxima ou evita essas atividades, o modo como interage com o espaço, com os materiais e com o terapeuta.

Winnicott, conforme Lins e Luz (1998) também dará ênfase não aos produtos gerados no decorrer do processo, mas aos próprios processos de constituição da pessoa que se atualizam numa experiência, na produção de sentido que é fazer, capaz de engajar o corpo e criar laços com um mundo compartilhado.

Daí, talvez, segundo Urrutigaray (2011), esse experienciar construir e se autoconstruir, trabaIhar com o homem de modo mais integrador, com uma visão mais ampla que possibilidade recuperar atividades que passem pelo corpo, trabalhando com técnicas expressivas que deem vez à linguagem do inconsciente. O universo da Arte, fundamentado na materialização de imagens mentais, por meio da produção, das manifestações durante a criação e da objetivação dos aspectos simbólicos, pode atuar, segundo Silveira (2001), como facilitador de purgação de tensões emocionais (catarses), também como medida preventiva ao embotamento psíquico e como propiciador de competências, para a noção de aquisição de esquemas de vida cotidiana. Jung (2011) mostrou-nos que a arte proporciona o trabalho com conteúdos simbólicos do inconsciente que podem ser submetidos à investigação psicológica, à medida que como modalidade terapêutica devem estar desprovidos de valor artístico, a fim de não serem submetidas a julgamentos estéticos, mas trazer à luz conteúdos psicoemocionais que podem ser compreendidos e trabalhados.

Nesse sentido, o presente artigo justifica-se não apenas por tratar de possibilitar a compreensão acerca das múltiplas causas e sintomas de uma inibição cognitiva, mas por apresentar alternativas de auxílio a profissionais que lidam com a inibição cognitiva ou com outras dificuldades de aprendizagem. Acreditamos que este estudo de caso trará contribuições relevantes para a compreensão desse aprisionamento da inteligência e do porquê dele, com base nos teóricos, mostrando a profissionais da saúde e da educação que um olhar holístico voltado ao sujeito, uma escuta apurada e intervenções adequadas podem remover obstáculos que impedem a circulação do conhecimento.

Além disso, objetivamos apresentar a Arteterapia como instrumento de diagnóstico e intervenção, podendo, sim, ser usada por psicopedagogos, visto que como modalidade terapêutica e expressiva possibilita a transformação de um indivíduo, sua individuação resultante da interação entre o criador- autor e a obra. Tendo o profissional, facilitador do processo, a incumbência de, por meio da utilização dos materiais plásticos e suporte, captar a projeção da personalidade do seu paciente nos seus aspectos mais profundos e inconscientes, promovendo nele atitudes adaptativas, projetivas, expressivas e consequentemente, transformadoras, fazendo vir à tona o secreto, libertando sua inteligência e possibilitando seus desenvolvimentos em todos os níveis e âmbitos do existir.

\section{Metodologia}

Este estudo foi delineado com base em pesquisa qualitativa, partindo de problematização da realidade, com a intenção de interpretar e compreender as características do fenômeno que abordamos, de uma forma flexível e que visa ao todo. Assim, ao utilizarmos esta abordagem, apresentamos este estudo de caso, enquanto consideramos que cada ser humano é único, possui subjetividade, atribui conceitos e possui vivências próprias.

Para tanto, realizamos uma coleta de dados por meio de sessões de entrevistas com os pais e com o garoto de oito anos, com quadro de inibição cognitiva, além disso, foram realizadas ses- 
sões diagnósticas, onde houve observação e avaliação por meio de atividades lúdicas centradas na aprendizagem, avaliação pedagógica, uso de provas e testes, bem como sessões de intervenção com utilização terapêutica de diversos instrumentos psicopedagógicos, principalmente, o uso daqueles que possibilitaram o trabalho com Arteterapia. A partir dos resultados obtidos e das hipóteses levantadas, realizamos um estudo aprofundado, confrontando-os com os aportes teóricos que versam sobre a temática abordada. Desta forma, destacamos que o presente artigo se trata de um estudo de caso, trazendo perspectivas relevantes às pesquisas já realizadas dentro do contexto da inibição cognitiva e da Arteterapia.

Baseando-se nos dados obtidos, o caso foi analisado sob a ótica psicopedagógica, fazendo-se o uso da de literatura apropriada. Primeiramente, procuramos dar sentido aos dados obtidos, a fim de compreender a temática estudada. Em segundo lugar, separamos os aspectos mais relevantes ao tema e, por fim, procuramos uma recontextualização dos dados com o referencial teórico escolhido para tal abordagem, demonstrando a importância da intervenção arte terapêutica no tratamento de crianças com inibição cognitiva e com outras dificuldades de aprendizagem.

Como procedimento ético, esta pesquisa valeu-se do "Termo de Assentimento Livre e Esclarecido", através do qual tratou das questões de contrato e sigilo. Ademais, cumprimos as "Resoluções Éticas Brasileiras", em especial a "Resolução CNS 510/16" (BRASIL, 2016), visando valorizar o respeito à dignidade humana e garantir proteção aos participantes da pesquisa.

\section{Descrição do caso}

João (nome fictício), acompanhado por sua mãe Ana (nome fictício), foi atendido por mim no NAPSI (Núcleo de Atendimento Psicopedagógico) de um centro universitário em Canoas, RS, durante o segundo semestre de 2012, quando eu realizava a prática de Estágio Clínico Supervisionado.

João tinha oito anos, cursava o 30 ano do Ensino Fundamental em uma escola da rede municipal de Canoas, onde sempre estudou, a qual o encaminhou com as seguintes queixas: o menino sempre foi bom aluno e, no entanto, no fim do primeiro semestre começou a apresentar problemas na escola, parecia ter esquecido tudo que já havia aprendido, estava muito agitado, inquieto, queixando-se e reclamando de tudo e de todos durante as aulas, colocava-se constantemente como vítima das situações que ocorriam em sala de aula, estava mais agressivo com os colegas, afastando-se dos mesmos e elegendo apenas um deles como seu único amigo, não demonstrava mais o interesse que sempre tivera em aula.

A mãe relatou que João era filho único, sempre foi um bom menino, uma criança tranquila e alegre. Entretanto, após a separação de seus pais no final de 2011, o garoto começou a apresentar problemas na escola e em casa. O menino tornou-se mais triste, introspectivo, mal-humorado e agressivo também com a mãe e com os avós maternos que moravam nas proximidades e cuidavam dele pela manhã, enquanto a mãe trabalhava em uma escolinha infantil em turno integral.

A mãe contou que desde que o pai saiu de casa, não conseguiu dizer ao filho os reais motivos da separação. O pai teve uma vida dupla, possuía outra mulher e, inclusive, outro filho, com dois anos de idade, fruto da relação extraconjugal. A mulher comentou que teve ciência de tudo, um ano antes da separação. Após a descoberta de traição, e antes do rompimento matrimonial, diante dos apelos e dos juramentos do ex-marido, deu-lhe uma chance de resolver sua vida e romper com a outra, que sabia que ele tinha família e era casado, mas isso não aconteceu. Então, Ana optou pelo divórcio. Disse que o ex-marido repetiu o comportamento do pai dele, que aban- 
O fazer arteterapêutico como abordagem de intervenção psicopedagógica desenvolvido com uma criança afetada por inibição cognitiva: um estudo de caso

donou a mulher com filhos ainda pequenos. A avó paterna de João já era, neste momento, falecida, o avô paterno nunca mais deu notícias desde o abandono do lar.

O menino, quando perguntava a respeito do fato recebia respostas postergadas, o silêncio dos pais provocava em João uma intensa ansiedade, raiva, sentimentos de culpa. Nada Ihe havia sido esclarecido até então e o pai tornou-se ausente.

Durante o período de diagnóstico, o menino não demonstrou grandes resistências, vinculou-se a mim facilmente, optei pela aplicação de técnicas e práticas artísticas expressivas como recurso investigativo, com a finalidade do exercício de trazer à luz conteúdos inconscientes, fantasias e sentimentos reprimidos, que ao serem objetivados, tornaram-se passíveis de serem trabalhados. Percebi que as atividades envolvendo desenho, pintura, modelagem o deixavam bem à vontade, livre e feliz.

A escuta ao paciente e a família, as observações realizadas durante o período diagnóstico, a escolha de instrumentos e procedimentos adequados aos interesses do garoto e apoiados em referenciais teóricos de suporte, a abordagem multidisciplinar realizada, o apoio de coovisão de minha orientadora e supervisora de estágio e o bom vínculo terapêutico estabelecido foi fundamental para o diagnóstico obtido: inibição cognitiva. Essa nada tem a ver com a transformação de uma função psíquica, com a alteração do pensamento, mas apresenta-se como diminuição, evitação ao contato com o objeto do pensamento (FERNÀNDEZ, 1991).

João, inconscientemente, teve uma resposta reativa. Por meio de um jogo (inconsciente) de saber/não saber travou seu conhecimento, inibiu-o, ocultou-o, evitando o saber. A separação dos pais, o segredo, o não dito, geraram no garoto um pedido de socorro.

Diante do sucesso inicial do tratamento, optei por seguir com as intervenções e investir no trabalho com a produção artística. Essa experiência possibilitou a reconstrução e a integração da personalidade de João, favorecendo o exercício de sua autonomia, possibilitando a transcendência de suas vivências imediatas, a experienciação de novos sentimentos, novas oportunidades, o estímulo à criatividade e à imaginação, possibilitando realmente a supressão da instabilidade psíquica. $O$ trabalho de Arteterapia com elaboração de autorretrato, desenhos da família, da escola, o uso das cores para expressar emoções, a escolha dos materiais para as projeções, a percepção das formas, o diálogo do paciente com a imagem produzida, pintura do corpo, representação de sua vida e de como gostaria que fosse, canções, elaborações de histórias em quadrinhos, escultura em argila, etc., proporcionaram a João a construção de obras de grande significado simbólico, onde os aspectos emocionais e cognitivos recalcados puderam ser confrontados e elaborados.

Outros aspectos a serem ressaltados sobre o tratamento é que a mãe de João aceitou encaminhamento para a psicóloga do Núcleo de Atendimento Psicopedagógico da instituição em que estava sendo atendido e trabalhamos a necessidade de dizer ao menino que o pai saíra de casa por optar outra vida com outra companheira, e que isso não afetaria o amor que sentia pelo filho. O pai também foi chamado para participar de algumas sessões individuais, com a mãe, e junto com o menino, com o intuito de que ele e a mãe do garoto entrassem num consenso em relação ao acontecido e contassem de forma compreensível ao menino o motivo do rompimento, dando a segurança com sua presença mais constante e participativa de que ele tinha um pai e não o perderia em função da separação.

Após um semestre de atendimentos psicopedagógicos, os trabalhos artísticos de João foram expostos no consultório, a pedido dele. Na escola, seu comportamento e seu rendimento melhoraram muito e para surpresa da professora o garoto idealizou e participou de uma exposição de 
artes na turma. Em casa, João alegre com a descoberta de suas potencialidades, efetuou com o pai a pintura de uma das paredes do quarto.

João fez questão de levar consigo todos os trabalhos produzidos durante o tratamento mas, entretanto, deixou comigo a certeza de que o psiquismo passa pelo corpo e de que as mãos podem falar mais do que o cérebro, a arte utilizada como ação terapêutica é capaz de acessar e mobilizar conteúdos emocionais, irracionais, ativando a fantasia e a criatividade, libertando o indivíduo e transformando sua vida por meio de experiências artísticas.

\section{Discussão}

De acordo com Bowlby (2006), após uma perda inesperada, há uma fase de protesto onde a pessoa que sofreu a perda se empenha em atitude pragmática ou psíquica e emocionalmente em recuperar a pessoa perdida e a culpa por seu abandono. Nesse momento, os sentimentos são ambivalentes, há a expectativa de recuperar o objeto amado ao mesmo tempo em que há o desespero e a raiva pela perda.

Freud (1999) sustentava que a perda de um dos pais dá origem à ansiedade a ao pesar, mas há processos em que a agressão desempenha um papel importante para superação do luto e para reconstrução psíquica do indivíduo. O menino João sentiu profundamente a perda de afeição dos pais um pelo outro, sentindo-se, com isso, rejeitado, vivenciando com a mãe o afastamento afetivo desta com o pai. Bowlby (2006) enfatiza que as crianças não só se afligem com a separação, como seu pesar é muito mais profundo e demorado do que supomos.

Psiquiatras e psicólogos concordam que para que o luto, a perda, leve a um resultado favorável é necessário que a pessoa que sofreu com aquele expresse seus sentimentos e emoções. Constata-se que alguém que passa pela perda de um ente querido sofre com o medo de ser abandonado, com a saudade e a raiva, pelo anseio de busca e reencontro, pela tendência de recriminar quem o deixou ou quem pareça responsável (BOLWBY, 2006).

Vimos que João sentiu a separação dos pais como uma perda, uma perda daquele pai que morava na mesma casa e assim deixava clara sua presença. Todos os comportamentos apresentados pelo menino, em casa e na escola, a agressividade, o mau humor, as queixas, a ansiedade, o não querer aprender refletiam a separação e a perda na família, devido ao rompimento de vínculos afetivos dos pais. Seu corpo expressava um pedido veemente de socorro.

Bowlby (2006) aponta que para darmos apoio a quem sofre uma perda é imprescindível vermos as coisas do ponto de vista deste e respeitar seus sentimentos, a fim de que a pessoa consiga expressar as esperanças, desejos, possibilidades improváveis, recriminações, remorsos, decepções, saudades, amargores. A ânsia, a raiva, o choro, o horror diante da solidão, a autocomiseração devem ser expressos para que possam ser descobertos e trabalhados.

Todos esses sentimentos e sensações são reações normais e saudáveis diante de tal circunstância, entretanto a grande e ou permanente intensidade deles, levando a prejuízos sociais ou a psicopatologias devem ser tratados e investigados. Em função da separação e principalmente do não-dito pelos pais em relação às causas da ruptura matrimonial, João teve atrapalhado o seu imaginário e travou seu desejo por conhecimento, obstruiu sua possibilidade de simbolizar. O não desejar aprender permitiu a João, de certa forma, manejar algumas situações, assim como a mudança comportamental que apresentou. O menino necessitava que o segredo fosse desvelado pelos pais para compreender, aceitar a situação e modificar-se. 
O fazer arteterapêutico como abordagem de intervenção psicopedagógica desenvolvido com uma criança afetada por inibição cognitiva: um estudo de caso

Fernández (1991) aponta que, para analisar as perturbações do aprendizado não devemos focar somente nas dificuldades apresentadas, tampouco simplificar todo transtorno reduzindo-o a razões afetivas ou à dinâmica familiar. Precisamos perceber a participação do desejo, do organismo, do corpo e da inteligência da criança na gestação de certas dificuldades, senão negaremos a possibilidade de sua participação em sua própria cura. O problema de aprendizagem é o processo subjetivo de anular as capacidades e bloquear as possibilidades.

Sara Paín (1991), crê que uma tarefa essencial no diagnóstico é resgatar o amor, evidenciar onde o amor é resgatável para o caminho da cura. Nos casos de inibição cognitiva, a pessoa, é o preso que constrói sua própria cela, como metaforiza Fernández. O indivíduo detém sua inteligência, aprisionando-a e aprisionando-se constantemente, diminuindo e evitando o contato com o saber, com o pensar em seu conjunto. Aí reside o papel do terapeuta, focar e evidenciar o que se tem de bom, de potencialidades, e não enfatizar o que falta, o que não se consegue, que se perdeu. $O$ terapeuta precisa ajudar o paciente a simbolizar o que se oculta e levar a pessoa a revelar o que ela não pode ou não quer revelar. Isso faz emergir do indivíduo o amor, a vida, a libertação de suas próprias amarras.

O saber se desvela, se constrói quando conseguimos fazer próprio o conhecimento do outro, segundo Fernández, e isso só podemos fazer jogando, proporcionando situações lúdicas. Conforme Piaget (2007) o desenho vincula-se ao jogo simbólico, pois por meio dele o sujeito imita, brinca com o real.

Lins e Luz (1998) comentam que Winnicott entusiasmou-se com o livre jogo criativo e por meio de uma técnica terapêutica breve usada com crianças, ele criou uma brincadeira que se tratava de desenhar, de rabiscar. $O$ terapeuta deveria fechar os olhos e fazer um rabisco à esmo no papel, o paciente deveria transformá-lo em alguma coisa e depois o paciente faria o mesmo feito inicial do terapeuta para que esse agora transformasse o seu traço. Por meio desse jogo, Winnicot estabelecia com a criança, uma relação mais primordial, por intermédio da imagem. O desenho a quatro mãos possibilita a fala pelas imagens; o papel é um espaço propício às potencialidades, demonstradas por gestos espontâneos.

Winnicott trabalha com o desenho não como algo acabado, mas como processo que manifesta a espontaneidade de um gesto, sua autonomia e o suporte fornecido pelo ambiente cultural. O risco rápido do desenho manifesta a espontaneidade inconsciente e ao mesmo tempo uma armação simples e lógica de uma intenção de projeto. Para o autor, a arte produz processos de subjetivação, o sujeito como processo ou devir, é experiência fundamental no processo e formação da personalidade. Winnicott privilegia a experiência no processo de arte em relação à interpretação do simbolismo inconsciente. $O$ pensador acredita que o procedimento clínico ligado à experiência artística deve ir além da interpretação de um tema revelado pela associação livre do paciente. Faz-se necessário, ao contrário, propiciar oportunidade para a experiência amorfa, para os impulsos criativos, motores e sensórios que são a matéria-prima do brincar.

O jogo dos rabiscos criado por Winnicott foi realizado com João. Esse foi visto por ele como "uma brincadeira muito divertida", possibilitando uma melhor comunicação e interação entre terapeuta-paciente. A imagem produzida transformou-se posteriormente em discurso, sentíamos como se estivéssemos jogando juntos, tendo cada um a oportunidade de sermos criativos. As instruções do jogo são bastante simples e fazem com que a criança se sinta livre, devido à ausência de normas fixas. Num clima de confiança, o paciente exprimiu de forma criativa suas fantasias, sua problemática, seus sonhos. $O$ terapeuta, recebendo essa comunicação, pôde reenviá-la a seu paciente de maneira criativa, com intimidade, alcançando e trabalhando com as angústias da criança. 
Klepsch e Logie (1984) acreditam que o desenho é uma das medidas que pode ser usada para o trabalho terapêutico dentro de uma abordagem de medidas múltiplas. Esse é capaz de perscrutar as profundidades interiores de uma pessoa e de revelar informações que, de outra forma, são inacessíveis. Pensam que os desenhos feitos pelos pacientes, isoladamente, não podem ser usados para avaliar uma pessoa, é preciso a observação, a conversa, outras fontes de informações. Não podemos fazer o julgamento sobre uma criança com base em sinais isolados, a impressão geral obtida de um desenho é mais importante que qualquer sinal, todavia é mais importante a percepção da criança conforme é vista no desenho e a tentativa de descobrir por que considera a situação da forma como o faz.

Edith Derdyk (2010) mostra-nos que a criança, como ser global, mescla suas manifestações expressivas, canta quando desenha, pode pintar o corpo ao representar, dança enquanto canta, desenha enquanto ouve histórias, representa enquanto fala. Por isso, por meio dessas diversas manifestações, se faz possível uma compreensão mais global da criança.

A autora diz que existem muitas teorias e interpretações a respeito das expressões plásticas e artísticas da criança, porém essas sem uma compreensão ao nível prático são vazias. É preciso ter cuidado para não impor sua própria imagem da infância ao interpretar o desenho da criança e compreender que esta desenha, entre outras coisas, para divertir-se, trazendo à tona por meio dessa atividade seus desejos interiores, comunicados, impulsos, emoções e sentimentos. Entretanto, nem toda criança gosta, necessariamente, de desenhar. Nesse caso, caberá ao adulto propor outras maneiras de intervenção ou cativar a criança para o desenho. A insistência exagerada do profissional em levar a criança a desenhar e em perguntas que exigem de forma implícita saber o que é aquilo, o que significa o que foi projetado pode inibir o processo de desenvolvimento gráfico figurativo da criança.

Derdyk (2010) diz que o desenho vai receber de seu autor uma interpretação, um comentário verbal, caracterizando-se como o prolongamento de sua ação. Essa, muitas vezes, é mais rica que o próprio desenho.

João estabeleceu um vínculo experiencial profundo como o desenho. Transformou-o em manifesto de sua identidade, evocou fatos vividos, ideias inconscientes, estimulou sua criatividade e imaginação, usou-o como ponte de comunicação entre a realidade vivida e suas fantasias, o desenho serviu como ponte entre terapeuta e paciente, possibilitou a ampliação de sua consciência. A partir do reconhecimento da sua própria capacidade de desenhar, surgiu um novo no encontro entre seus pais e ele.

A utilização de marcas gráficas no papel aproximou João de seu mundo, de si mesmo, propiciou a aceitação e as transformações necessárias em seu eu. Seus desenhos não foram estanques, expressaram a maneira pela qual se sentia existindo e experienciando novos sentimentos e vivências. O mais importante no decorrer das intervenções não é apenas compreender os conteúdos e as significações simbólicas do desenho, mas possibilitar a experiência da criança com ela mesma e com o seu meio, bem como a compreensão desses. O importante não é apenas projetar e alterar o espaço do papel, mas alterar seu espaço interior e exterior.

Mesmo que o objetivo primordial da Arteterapia não seja deter-se a interpretação das criações, sabemos que as cores revelam muito das emoções. Neste aspecto, Urrutigaray (2011) mostra-nos, por exemplo, que o preto reflete menos luz, simboliza a ideia do nada, da renúncia, do abandono, do não, da morte, do luto. João, inicialmente, usou muito o preto para expressar seu luto, posteriormente em função de sua manifestação e percepção, esse conteúdo esgotou-se em suas manifestações artísticas e se transformou, dando vazão a outras cores e formas. 
O fazer arteterapêutico como abordagem de intervenção psicopedagógica desenvolvido com uma criança afetada por inibição cognitiva: um estudo de caso

Em vista disso, é possível concordar com Urrutigaray de que as cores têm fortes propriedades expressivas que estão relacionadas aos estados emocionais de quem as percebe e/ou as utiliza. Jung (2001) acreditava que elas exprimem as principais funções psíquicas do homem, embora variando suas interpretações.

João tinha fascinação por determinado super-herói japonês, pedia para desenhá-lo para que eu pudesse ver o quão bem ele sabia fazê-lo; sempre o fazia com a sua turma (o super-herói e seus amigos super-heróis). Realmente seus desenhos eram muito bem elaborados, como de um adulto, bem como as pinturas que por vezes fazia. Certa vez, quando o elogiei e perguntei-lhe $o$ porquê do gosto pelo personagem, o menino respondeu-me que ele gostaria de ser como esse super-herói e ter muitos poderes, ter muitos amigos.

Deste modo, não fiz apenas uma leitura das imagens feitas pelo garoto, observei seus modos de atuar, de sentir, de se posicionar diante do material e, principalmente, seu discurso. Talvez João, diante daquelas circunstâncias pelas quais passava, realmente desejava ser um super-herói, para suportar todos os obstáculos da vida, para não se sentir frágil, para não precisar de ninguém que pudesse abandoná-lo. O super-herói tinha muitos amigos, João almejava tê-los também; em seu imaginário, se fosse outra pessoa, um herói, conquistaria também muitos amigos, amigos que, na realidade não conseguia fazer em suas relações.

Urrutigaray (2011) diz que a terapeuta deve tentar fazer com que o paciente (o criador) se aproxime mais de si mesmo, por meio do desenvolvimento de suas potencialidades, da descoberta de aspectos ainda desconhecidos sem, contudo, forçar análises que ainda não conseguem ser assimiladas.

João sempre preferiu usar materiais secos (lápis, canetas hidrográficas, gizes de cera) e trabalhar com a técnica do desenho. Urrutigaray (2011) acredita que os materiais plásticos promovem o fluxo energético dos processos intrapsíquicos, propiciam a manifestação de impulsos agressivos e de defesas, facultam a sensação do domínio do real e o tipo de material escolhido também é elemento indicativo de estados emocionais, internos, bem como os tipos de linhas e de consistência dos traçados, da maneira como o lápis é segurado.

Jung (2001) pensa que as imagens englobam conjuntos de significações representativos de padrões pessoais sentidos e vividos por um indivíduo, mas também são portadoras de um ideal arquetípico mais transcendente e de caráter geral, levando-nos a verificar que o fazer humano sempre revelou uma necessidade de expressão típica do homem, comunica suas qualidades transcendentes e ao mesmo tempo vincula o homem consigo mesmo e com o seu meio. Assim, acentuamos que a capacidade de exercer o ato criativo é tão natural quanto outras necessidades e todas as pessoas possuem um potencial criador.

\section{Considerações finais}

Compreender as causas e o funcionamento da inibição cognitiva é também competência da Psicopedagogia, por meio da escuta, da observação e da interação com o paciente e com a sua história de vida.

Libertar o indivíduo da inibição, entendida no sentido freudiano como limitação normal de uma função que não tem necessariamente uma implicação patológica, é tarefa do psicopedagogo (PAín, 1991). Para tal, se faz necessário compreender o outro em sua condição integral, percebendo a dimensão do corpo na aprendizagem. 
Quando o segredo, o não-dito atrapalha a relação da criança com o conhecimento, quando a criança percebe que é impedida de perguntar, quando o conhecimento da verdade é velado a ela e ela não pode expressar-se surge, então, um obstáculo no nível do desejo impedindo a circulação do saber.

A Arteterapia (URRUTIGARAY, 2011) apresenta-se a nós como modalidade expressiva e terapêutica que, partindo de realizações concretas, de criação de trabalhos pessoais, de fazer o secreto, o inconsciente vir à tona, desobstruindo canais que impedem a estruturação de uma identidade, possibilita o sentimento de aceitação, compreensão e inclusão, propiciando ao indivíduo compreender suas dimensões simbólicas contidas nas suas representações.

Acreditamos que o trabalho com arte canaliza os impulsos e as emoções inflacionadas e as atitudes compulsivas em projeções, possibilitando a reintegração de todas as dimensões de pessoa.

\section{Referências}

BOWLBY, John. Formação e rompimento dos laços afetivos. 4. ed. São Paulo: Martins Fontes, 2006.

BRASIL. Ministério da Saúde. Conselho Nacional de Saúde. Resolução no 510, de 07 de abril de 2016. Dispõe sobre as normas aplicáveis a pesquisas em Ciências Humanas e Sociais. Diário Oficial da União, Brasília, DF, 24 mai. 2016. Seção 1, p. 44-46. Disponível em: http://bit.ly/2fmnKeD. Acesso em: 01 set. 2020.

DERDYK, Edith. Formas de pensar o desenho: desenvolvimento do grafismo infantil. 4. ed. São Paulo: Zouk, 2010.

FERNANDEZ, Alicia. A inteligência aprisionada: abordagem psicopedagógica clínica da criança e sua família. 2a reedição. Porto Alegre: Artmed, 1991.

FREUD, Sigmund. Chaves-resumo das obras completas. 1a ed. São Paulo: Atheneu, 1999.

JUNG, C. G. A prática da psicoterapia. 13. ed. Petrópolis, RJ: Vozes, 2011.

O Espírito na Arte e na Ciência. 6a. edição. RJ: Vozes, 2011.

Os Arquétipos e o Inconsciente Coletivo. 7a. edição. RJ: Vozes, 2011.

KLEPSCH, Marvin; LOGIE, Laura. Crianças desenham e comunicam: uma introdução aos usos projetivos dos desenhos infantis da figura humana. Porto Alegre: Artes Médicas, 1984.

LINS, Maria I.A; LUZ, Rogério. D. W. Winnicott: experiência clínica \& experiência estética. 1ạ ed. Rio de Janeiro: Revinter, 1998.

PAín, Sara. A função da ignorância. Porto Alegre: Artes Médicas, 1991. 2. v.

PIAGET, Jean. Epistemologia genética. Tradução Álvaro Cabral. 3ạ ed. - São Paulo: Martins Fontes, 2007.

Pichon-Rivière, Enrique. Teoria do Vínculo. São Paulo: Martins Fontes, 2007. 
O fazer arteterapêutico como abordagem de intervenção psicopedagógica desenvolvido com uma criança afetada por inibição cognitiva: um estudo de caso

SILVEIRA, Nise da. 0 mundo das imagens. São Paulo: Ática, 2001.

URRUTIGARAY, Maria Cristina. Arteterapia: a transformação pessoal pelas imagens. 5. ed. Rio de Janeiro, Wak, 2011.

VYGOTSKY, Lev Semenovich; LURIA, Alexander Romanovich; LEONTIEV, Alex Nikolaevich. Linguagem, desenvolvimento e aprendizagem. São Paulo: Ícone, 1988.

WEISS, Maria Lucia Lemme. Psicopedagogia clínica - uma visão diagnóstica dos problemas de aprendizagem escolar. 13a ed. Rio de Janeiro: Lamparina, 2008. 